\title{
HISTORY AND LEGAL STATUS OF THE RESTRICTED CAMPS FOR WAR PRISONERS OF THE WEHRMACHT IN STALINGRAD $(1947-1949)^{1}$
}

\author{
Aleksandr E. Epifanov \\ Volgograd State University, Volgograd, Russian Federation
}

\begin{abstract}
Introduction: in the article from the standpoint of history and law, on the example of the city of Stalingrad, the author considers the organization and activities of the restricted camps of the Ministry of Internal Affairs of the USSR for the Wehrmacht war prisoners formed in the second half of 1940-ies in order to avoid the repatriation to the homeland of the persons involved in war crimes during the Great Patriotic War. For this purpose, through the use of the archival materials, the author analyzes such forms and methods of these camps' activities as the strict isolation of their population with the establishment of reinforced regimen; carrying out the operational search and investigative actions aimed at identifying and bringing Hitler's war criminals to criminal responsibility, as well as the persons who served in the organizations recognized as criminal ones during the war; labor use of the prison population to restore the Soviet economy destroyed during the war, as well as the construction of the largest domestic and industrial facilities. With the help of the methods of scientific knowledge, especially the method of historicism, the order of accounting and registration of prisoners of war, allotted from repatriation, their maintenance and labor, resistance and opposition to the camp administration were generalized. Results: the author summarizes and analyzes the order of the organization of the restricted camps of the Ministry of Internal Affairs of the USSR for the Wehrmacht prisoners of war, allotted from repatriation, as well as the practice of its implementation; identifies and introduces into scientific circulation the normative legal acts, including the departmental ones concerning the organization and activities of these camps; analyzes the reports and statistical data on the studied problem; shows the reasons and conditions that caused unjustified repression for political reasons of prisoners of war, without proper proof of their guilt, which in turn led to the need for rehabilitation measures in their cases at the present time. Conclusions: in the second half of 1940-ies in the Soviet Union a significant part of the POWs of the Wehrmacht was allotted from repatriation to the homeland, under the pretext of their participation in Nazi atrocities during the Great Patriotic War and service in the organizations recognized as criminal ones. For their maintenance, operational and investigative analysis and labor use a number of specialized restricted camps were organized by the Ministry of Internal Affairs of the USSR, and for a large part - on the territory of Stalingrad and its environs. The detention of the prisoners of war in the restricted camps was in itself one of the measures of extrajudicial repression against them, and for a large part - also a preliminary stage of criminal prosecution, mainly on charges of war crimes.
\end{abstract}

Key words: war criminals, prisoners of war of the Wehrmacht, Stalingrad, Internal Affairs Bodies, camps, filtration.

Citation. Epifanov A.E. History and Legal Status of the Restricted Camps for War Prisoners of the Wehrmacht in Stalingrad (1947-1949). Legal Concept, 2018, vol. 17, no. 3, pp. 70-78. DOI: https://doi.org/10.15688/lc.jvolsu.2018.3.10

УДК 34.096

ББК 67.3

ИСТОРИЯ И ПРАВОВОЕ ПОЛОЖЕНИЕ РЕЖИМНЫХ ЛАГЕРЕЙ ДЛЯ ВОЕННОПЛЕННЫХ ВЕРМАХТА В СТАЛИНГРАДЕ $(1947-1949 \text { гг. })^{1}$

\author{
Александр Егорович Епифанов
}

Волгоградский государственный университет, г. Волгоград, Российская Федерация 
Введение: в статье с историко-правовых позиций на примере города Сталинграда рассматриваются организация и деятельность режимных лагерей МВД СССР для военнопленных вермахта, образованных во второй половине 1940-х гг. для того, чтобы не допустить репатриацию на родину лиц, причастных к военным преступлениям в период Великой Отечественной войны. С этой целью, благодаря использованию архивных материалов, автором анализируются такие формы и методы деятельности названных лагерей, как: строгая изоляция их контингента с установлением усиленного режима содержания; проведение оперативно-розыскных и следственных действий, направленных на выявление и привлечение к уголовной ответственности гитлеровских военных преступников, а также лиц, проходивших в годы войны службу в организациях, признанных преступными; трудоиспользование контингента на восстановлении разрушенного в период войны советского народного хозяйства, а также на возведении крупнейших бытовых и промышленных объектов. С помощью методов научного познания, прежде всего метода историзма, были обобщены порядок учета и регистрации военнопленных, отведенных от репатриации, их содержания и трудоиспользования, сопротивления лагерной администрации и противодействия ему. Результаты: автором обобщены и проанализированы порядок организации режимных лагерей МВД СССР для военнопленных вермахта, отведенных от репатриации, а также практика его осуществления; выявлены и введены в научный оборот нормативно-правовые акты, в том числе ведомственные, касающиеся организации и деятельности названных лагерей; проанализированы отчетность и статистические данные по исследуемой проблеме; показаны причины и условия, повлекшие необоснованное репрессирование по политическим мотивам военнопленных без надлежащего доказывания их вины, повлекшее в свою очередь необходимость проведения реабилитационных мероприятий по их делам в настоящее время. Выводы: во второй половине 1940-х гг. в Советском Союзе от репатриации на родину была отведена значительная часть военнопленных вермахта под предлогом их участия в гитлеровских злодеяниях в период Великой Отечественной войны и службы в организациях, признанных преступными. Для их содержания, оперативно-следственной разработки и трудоиспользования МВД СССР был организован ряд специализированных режимных лагерей, причем для значительной части - на территории Сталинграда и его окрестностей. Пребывание названных военнопленных в режимных лагерях само по себе явилось одной из мер внесудебной репрессии в отношении них, а для значительной части - также предварительной стадией уголовного преследования, главным образом по обвинению в военных преступлениях.

Ключевые слова: военные преступники, военнопленные вермахта, Сталинград, органы внутренних дел, лагеря, фильтрация.

Цитирование. Епифанов А. Е. История и правовое положение режимных лагерей для военнопленных вермахта в Сталинграде (1947-1949 гг.) // Legal Concept = Правовая парадигма. - 2018. - Т. 17, № 3. - C. 7078. - DOI: https://doi.org/10.15688/lc.jvolsu.2018.3.10

\section{Введение}

Образование режимных лагерей для военнопленных явилось воплощением планомерной и продуманной политики руководства органов внутренних дел СССР, нашедшего в этом вопросе поддержку партии и правительства Советского государства. Ее основной целью было разделение военнопленных на лиц, подлежащих освобождению в 1947-1948 гг., и оставляемых в лагерях МВД после 1948 г. с последующей концентрацией последних в тыловых, специально организованных лагерях и их привлечение к ответственности, в основном по обвинению в злодеяниях на оккупированной территории СССР. Всего на «особом учете» органов МВД СССР состояли 41297 пленных, ранее проходивших службу в формированиях и учреждениях карательного и специального назначения гитлеровской Германии. Решение вопроса об их репатриации советским правительством было отложено до четвертого квартала 1949 года. До этого времени их сосредоточили в режимных лагерях МВД СССР «для военнопленных, отведенных от репатриации на родину». Учитывая актуальность борьбы с нарушениями законов и обычаев войны на современном этапе, а также реабилитационные мероприятия в отношении жертв политических репрессий, возникает интерес к истории и правовому регулированию организации и деятельности названных лагерей, а также правовому положению их контингента.

\section{Организация режимных лагерей МВД СССР}

Конкретное обсуждение необходимых для этого мероприятий явилось одной из основных тем оперативного совещания замес- 


\section{ТЕОРИЯ И ПРАКТИКА ГОСУДАРСТВЕННО-ПРАВОВОГО РАЗВИТИЯ}

тителей министра внутренних дел СССР, состоявшегося 6 июня 1947 года. Разработанные на нем предложения были утверждены министром и в качестве первого пункта предусматривали изоляцию от остальной массы военнопленных бывших сотрудников и военнослужащих органов и войск СС, СА, СД, Гестапо, участников зверств и других преступлений на территории СССР, злостных саботажников, беглецов, «промотчиков казенного имущества», расхитителей и т. п.

Первоначально предполагалось сосредоточить до 1 октября 1947 г. указанный контингент в специально отведенных тыловых лагерях в восточной части СССР (на Урале и в Сибири). С этой целью руководителям Главного управления по делам военнопленных и интернированных (ГУПВИ) МВД СССР И.А. Петрову и А.3. Кобулову было поручено до 1 июля этого же года полностью учесть наличие особого контингента по каждому лагерю МВД в отдельности. Им же отводилась разработка конкретных мероприятий по его сосредоточению, режиму содержания, охране и оперативному обслуживанию. Предназначенные для указанных военнопленных лагеря были отнесены к группе особорежимных, что выражалось в организации надежной охраны с применением специально подобранных гарнизонов конвойных войск, усиленных в режиме содержания и оперативном составе [8, л. 3-7]. В последующем, во всех лагерях, отдельных рабочих батальонах и спецгоспиталях военнопленных был произведен тщательный учет и одновременно изоляция «особого контингента».

\section{Реорганизация сталинградских лагерей МВД СССР для военнопленных}

\section{в режимные}

В августе 1948 г. руководством советских органов внутренних дел было принято решение о сосредоточении в режимных лагерях на строительствах Главгидростроя МВД СССР всех военнопленных, не подлежащих репатриации и осужденных военными трибуналами. 18 августа того же года приказом МВД СССР сталинградский лагерь военнопленных № 108 был преобразован в режимный. Его основной производственной задачей ста- ло обеспечение строительства соединительного канала Волга - Дон. В этом отношении он переходил в ведение Главгидростроя МВД СССР. Максимальное количество его заключенных первоначально было определено в 8000 человек. В состав режимного лагеря № 108 вошли 4 лагерных отделения: № 1 около Кирпичного завода в Красноармейском районе Сталинграда - на 3000 заключенных; № 2 у Нефтебазы Красноармейского района - на 2 600; № 3 на станции Жирново Тацинского района; № 4 на станции Репное Каменского района Ростовской области - на 800 заключенных. Кроме того, во втором лагерном отделении предусматривались две «подкомандировки» (лагерных пункта) при лесокомбинатах заводов им. Ермана и Куйбышева в Кировском районе Сталинграда - по 200 человек. Первые военнопленные прибыли на «особый режим» в сентябре 1948 года. До декабря их временно разместили в бывшем 1-м лаготделении прежнего лагеря № 108 при заводе № 264 в Красноармейском районе Сталинграда [7, л. 40].

К этому времени, в связи с производственной необходимостью и сложностями в размещении военнопленных, режимный лагерь МВД № 108 несколько изменил свое расположение. Первое лагерное отделение передислоцировалось непосредственно к устью строящегося канала и расположилось при «Строительстве № 1». Количество заключенных в нем достигло 2237 . Лагерное отделение № 2 временно разместилось в поселке Веселая балка Кировского района Сталинграда (при электростанции СталГРЭС). В нем было всего 309 военнопленных. Впоследствии оно также передислоцировалось в лагерный городок поселка Красноармейск для обслуживания Строительного района № 1 соединительного канала Волга - Дон. В поселке Бекетовка при заводе им. Ермана расположилось 3-е лагерное отделение с 418 заключенными. Здесь же развернули центральный лазарет 108-го лагеря, в котором на 30 ноября 1948 г. лечились 134 военнопленных. Лагерное отделение № 4 представляло собой подсобное хозяйство лагеря № 108 и находилось в селе Цаца Красноармейского района. На нем работали 71 заключенный. На заводе им. Куйбышева в поселкеЕльшанка Ворошиловского района Сталин- 
града работали 435 военнопленных 5-го лагерного отделения, располагавшегося там же. Своей максимальной отметки количество заключенных в режимном лагере № 108 достигло в январе 1949 г. - 4616 человек, в том числе 3670 немцев [5, л. 54].

По воспоминаниям ветеранов, положение заключенных в нем мало чем отличалось от обычных лагерей военнопленных, разве что более строгой охраной. Бывший заместитель начальника лагерного отделения № 1 по политической части Д.А. Тюленев рассказывает, что строившие канал заключенные долгое время жили в палатках. Они возводили главным образом 1-й шлюз, а также производили самые значительные и сложные отделочные работы. Для этого со всех лагерей были собраны лучшие мастера. Военнопленным были доверены даже строительство и отделка гигантского монумента И.В. Сталину, который был установлен у входа в канал.

\section{Регламентация порядка содержания в режимных лагерях}

В октябре 1949 г. в недрах МВД СССР было разработано положение о режимных лагерях, предназначенных «для содержания подучетного контингента из числа военнопленных и интернированных, не подлежащих согласно приказам и директивам МВД СССР репатриации» [6, л. 122-129]. По имеющимся сведениям, министром внутренних дел СССР С.Н. Кругловым оно утверждено не было. Однако его текст был распространен для руководства в соответствующих местах содержания режимных категорий военнопленных, в 108-м лагере в том числе. В соответствии с указанным документом, в режимные лагеря направлялись военнопленные и интернированные, состоящие на оперативном учете по спискам, утвержденным министрами внутренних дел республик, начальниками УМВД краев и областей либо их заместителями. Конвоирование заключенных в режимные лагеря производилось только в тюремных или специально оборудованных вагонах исключительно конвойными войсками МВД. В соответствии с текстом положения, все военнопленные по прибытии в режимный лагерь прежде всего подлежали тщательному обыску сотрудника- ми охраны и режима с участием оперативных работников и переводчиков. Изъятию подлежали запрещенные к хранению записи и предметы (такие как топографические и географические карты, бинокли, компасы, фотоаппараты, оружие и острорежущие предметы), а также все без исключения ценные изделия из благородных металлов, иностранная валюта и советские деньги сверх разрешенной суммы.

Военнопленные и интернированные режимного лагеря подлежали размещению строго по национальному признаку и по бригадам (отделениям, взводам). Во главе указанных подразделений по согласованию с оперотделом назначались старшие из среды самих заключенных. Офицеры размещались отдельно от рядового и унтер-офицерского состава. Для поддержания порядка в зоне лагерного отделения, а также в бараках, из числа военнопленных назначались комендант зоны и старшие бараков. Коменданты зон, старшие бараков и бригадиры по отношению к подчиненным военнопленным и интернированным дисциплинарными правами не пользовались. Свободное перемещение заключенных в зоне режимного лагеря допускалось только от подъема и до сигнала «отбой ко сну». В оставшееся время всякое передвижение людей в зоне лагеря запрещалось, за исключением лиц суточного наряда и естественной надобности. Продуктами питания и вещевым довольствием режимные заключенные обеспечивались в соответствии с нормами, установленными для военнопленных.

Охрана и порядок содержания контингента в режимных лагерях были организованы таким образом, чтобы обеспечить его надежную изоляцию и исключить всякую возможность побега. Охрану военнопленных в зонах лагеря, лагерных отделений, а также на объектах работ осуществляли только подразделения конвойных войск МВД. Вывод военнопленных и интернированных на работы без войсковой охраны категорически запрещался. Расконвоирование заключенных и организация вспомогательных команд в режимных лагерях не допускались.

Места работы режимных категорий военнопленных и интернированных в обязательном порядке ограждались колючей проволо- 


\section{ТЕОРИЯ И ПРАКТИКА ГОСУДАРСТВЕННО-ПРАВОВОГО РАЗВИТИЯ}

кой или деревянным забором. На те объекты работ, где отсутствовали надлежащие ограждение и освещение, режимных заключенных выводить запрещалось. Предусматривались строгие меры по осмотру и тщательной проверке военнопленных и интернированных при их возвращении с работы, без принятия которых допуск заключенных в зону был запрещен. В целях обнаружения и изъятия у военнопленных и интернированных запрещенных к хранению предметов в бараках режимного лагеря не менее двух раз в месяц производились внезапные обыски.

Содержащиеся в режимном лагере военнопленные и интернированные, за исключением больных, а также заключенных, не выводящихся на работу «по оперативным соображениям», привлекались к работе в обязательном порядке. Текст положения содержал примечание о том, что весь офицерский состав немецкой национальности в соответствии с их физическим состоянием, до капитана включительно, привлекается к контрагентским работам на общих основаниях с остальными военнопленными. Офицерский состав в звании выше капитана использовался на работах только по их желанию, оформлявшемуся личными рапортами на имя начальника Управления лагеря. Все работы, выполнявшиеся заключенными режимного лагеря, должны были нормироваться и оплачиваться на основании действовавшего Положения о военнопленных. Продолжительность рабочего дня для военнопленных и интернированных устанавливалась в 8 часов. Для не выполнявших нормы выработки лагерной администрации и хозяйственным органам разрешалось увеличивать рабочий день с учетом физического состояния заключенных до 10 часов в сутки. Помимо общих праздничных дней, режимным заключенным предоставлялся полный выходной день через каждые 6 дней работы. Условия работы военнопленных и интернированных в режимных лагерях должны были отвечать следующим требованиям: полная изоляция заключенных во время работы от окружающего населения и от другой рабочей силы; эффективное использование военнопленных и интернированных; постоянное наблюдение за их работой со стороны административно-технического состояния хозяйственных органов.
Основными формами и методами политической работы в режимном лагере, которые закрепил текст положения, являлись, как и прежде, читки газет и литературы, беседы, собрания, митинги, лекции, кружки и курсы, демонстрация кинофильмов, художественная самодеятельность и организация трудового соревнования среди заключенных.

Судя по имеющимся архивным материалам, местные органы внутренних дел при комплектовании контингентов режимных лагерей руководствовались также распоряжением заместителя наркома внутренних дел СССР В.В. Чернышева, изданным еще в 1944 г. [1, л. 94-95]. Последнее предусматривалось для первых режимных лагерей, организованных на территории СССР: Карагандинского № 99 и Суслонгерского № 171. В соответствии с ним, направлению на особый режим подлежали военнопленные офицеры и приравненные к ним солдаты следующих категорий:

1. Участники зверств и злодеяний, совершенных на территории СССР и в оккупированных странах Европы. Основанием при этом служили «достаточно проверенные» материалы о совершении ими военных преступлений, такие как личное признание (независимо от приказа), свидетельские показания и достоверные оперативные данные.

2. Активные фашисты, сотрудники и агенты разведывательных и контрразведывательных органов гитлеровской Германии и ее союзников, активные участники карательных органов и отрядов, бывшие агенты-двойники, внедрявшиеся в секретную сеть органов НКВД с «вражескими замыслами». К этой категории относились бывшие военнослужащие и сотрудники «зондеркоманд», частей СС, тайной полевой полиции, Гестапо, концлагерей для советских военнопленных, комендатур, разведывательных и контрразведывательных органов; лица, проявившие себя в борьбе с партизанами и при проведении репрессий мирного советского населения, принимавшие участие в ограблении советских граждан; военнопленные, отличившиеся «как фашисты», и разоблаченные «агенты-двойники».

3. Пытавшиеся бежать из лагерей и задержанные пленные, а также лица, проявлявшие активные намерения (подтверждавшие- 
ся «проверенными» оперативными и следственными материалами) к организации и совершению побегов из лагерей.

\section{Движение сопротивления контингента режимных лагерей и борьба с ним}

Руководство режимного лагеря № 108 отмечало в своей отчетности за 1 квартал 1949 г., что лагеря военнопленных, направляя своих заключенных на особый режим, проявили несерьезное отношение к отбору соответствующего контингента. Из 4041 человека, прибывших в сентябре 1948 г., на централизованном оперативном учете оказались только 2 521. Значительная часть подучетного элемента, поступившего из разных лагерей, была направлена к ним неправильно. Так, на 12 человек, прибывших из лагеря № 260, никаких компроментирующих материалов не было; лагерь № 185 на особый режим направил военнопленных по признакам их принадлежности к НСДАП и Гитлерюгенд, что само по себе основанием для этого не являлось. Очевидно, что данные обстоятельства самым негативным образом повлияли на качество мероприятий, проводимых в рамках фильтрации военнопленных.

По мере того, как надежд на возвращение домой оставалось все меньше, среди заключенных режимного лагеря № 108 крепло движение сопротивления, принимавшее самые разнообразные формы. Большое распространение получают такие проявления «враждебной деятельности» военнопленных, как членовредительство и доведение себя до физического истощения. Все чаще проявления сопротивления принимают организованный характер, а ответные меры лагерной администрации становятся более жестокими. К примеру, бывший шофер дивизии СС «Мертвая голова» К. Венцель, военнопленный режимного лагеря № 108/1, 25 декабря 1948 г. перед выходом на работу обратился к своей бригаде (25 человек). Он призвал в организованном порядке собрать вещи и 1 января 1949 г. выйти к проходной будке с заявлением, что они собрались домой. При этом Венцель заверял своих товарищей, что в организованную толпу конвой стрелять не станет [2, л. 6]. За указанную «враждебную деятель- ность» Венцель по ст. 19-58-14 УК РСФСР («Контрреволюционный саботаж») был приговорен к 10 годам исправительно-трудовых лагерей (ИТЛ).

В связи с «определенной задержкой репатриации» лагерные оперативники отмечали значительное усиление «отрицательных и враждебных настроений» среди военнопленных, что было особенно характерно для 4 квартала 1948 года. К числу «наиболее типичных» высказываний военнопленных по этому поводу относились, например, такие:

- Россия делает большую ошибку в том, что военнопленных так плохо содержат и так долго задерживают. Конечно, когда мы приедем домой, то кто из нас сможет говорить хорошо о Советском Союзе? Кто из тех военнопленных, которые были в Советском Союзе, в будущей войне избежит того, чтобы добровольно и охотно взять оружие в руки и пойти воевать против СССР? Из России здоровым и работоспособным не уедешь, можно уехать только инвалидом [6, л. 7].

Бывший рядовой 17 отдельного учебноразведывательного батальона СС Г. Гаусман с горечью писал своим родителям из 1-го лагерного отделения:

- В СС я был всего лишь 4 недели, а в плену нахожусь уже свыше 4 лет и конца этому не видно. Здесь не делают никакого различия между настоящими нацистами и теми, кто не по своей воле служил в войсках СС, пусть даже всего 4 недели [3, л. 107].

В этот же период и по тем же причинам значительно активизируются «побеговые настроения» военнопленных, особенно со стороны подучетного элемента. Например, лагерным чекистам стало известно высказывание обер-ефрейтора, члена СА А. Мительштадт такого рода:

- Если я в этом 1948 г. не буду отправлен на родину, то при любых обстоятельствах совершу побег из лагеря, ибо мне все равно - или жить в плену, или умереть при побеге [6, л. 7].

В целом по режимному лагерю № 108 в 4 квартале 1948 г. в штрафную роту были переведены 17 военнопленных, выражавших подобные настроения. Администрация лагеря отмечала неудовлетворительное обеспечение должной охраной подучетного элемента. Оно существенно затруднялось тем, что на боль- 


\section{ТЕОРИЯ И ПРАКТИКА ГОСУДАРСТВЕННО-ПРАВОВОГО РАЗВИТИЯ}

шинстве объектов места работ заключенных огорожены не были (хотя это и было предусмотрено проектом положения о режимных лагерях). Как крайне неудовлетворительное характеризовалось несение службы личным составом 318 конвойного полка. Его военнослужащие так и не прониклись «чувством особой ответственности» за охрану режимного контингента военнопленных. Грубейшие нарушения конвойной службы с их стороны носили характер системы. Имели место, например, такие случаи:

a) 9 февраля 1949 г. рядовой Д.В. Кравцов, охраняя группу военнопленных на работах СталГРЭС, оставил их без присмотра и ушел к девушкам в строящееся на расстоянии 200 метров здание; б) 16 февраля 1949 г. конвоир Е.Р. Ефименко, приняв под охрану группу военнопленных, вывел их за зону и, оставив одних, ушел в санчасть. Заключенные, пройдя 300-400 метров и обнаружив отсутствие Ефименко, вернулись в лагерное отделение.

Во многих случаях при проверках обнаруживали конвоиров, которые, покинув охраняемых, уходили спать. Вследствие крайне неудовлетворительной охраны военнопленных режимного лагеря № 108 в 1948 г. совершили побег 10 заключенных, из которых удалось задержать только 9. В 1949 г. бежали двое, из них задержан один. Ввиду создавшегося положения, которое представляло серьезную угрозу, администрация лагеря вынуждена была обратиться для принятия мер в Управление конвойных войск МВД СССР [6, л. 7].

В связи с проводимой фильтрацией администрация лагерей всеми имевшимися в ее распоряжении средствами, а также силами конвойных войск, поддерживала порядок, исключающий возможные попытки со стороны «наиболее активного фашистского элемента» совершать какие-либо акты саботажа на производстве, где использовались военнопленные. Специальные меры предосторожности предпринимались по недопущению эксцессов в виде голодовок, побегов и другой деятельности «реакционных групп военнопленных». Их инициаторов и организаторов предписывалось арестовывать и привлекать к уголовной ответственности.

Несмотря на активные политические мероприятия, проводимые органами МВД и антифашистскими группами, а также показа- тельные репрессивные меры по отношению к «реваншистски настроенным» заключенным, оперативники фиксировали все более резкие политические суждения и критику в адрес лагерной администрации со стороны военнопленных. Проявления сопротивления с их стороны начинают принимать агрессивный характер. Чекистами режимного лагеря № 108/1 в апреле 1949 г. из разговоров между заключенными были зафиксированы следующие «важные данные» на этот счет:

- Я служил в общих войсках СС, был активным членом нацистской партии, ранее служил в иностранном легионе «Кондор», участвовал в гражданской войне в Испании, где был награжден золотым испанским крестом за зверское отношение к антифашистам и противникам Франко. В Испании мы очень много расстреляли антифашистов. Если меня отпустят из лагеря, то я поеду в Испанию, так как Франко хорошо поощряет солдат. С 1941 г. я участвовал в войне против СССР в составе дивизии «Лейбштандарт - Адольф Гитлер». За участие в боях против Советской армии и партизан я награжден рыцарским крестом с дубовыми листьями. Здесь в лагере очень много агентуры, которая доносит в МВД. Таких субъектов надо немедленно уничтожать, ибо они очень опасны. Пока с ними надо обращаться хорошо, а по дороге домой рассчитаться. Англичане и американцы обратят особое внимание на таких шпионов. В лагерях СССР погибло очень много немцев и венгров, $80 \%$ из них замучено или погибло от голода. В Сибирь, на Урал и в Караганду привезли сотни тысяч немецких женщин и детей из Восточной Пруссии и Силезии. Их используют на принудительных работах и бесчеловечно к ним относятся. Поэтому их не отпускают домой, чтобы они не рассказали об отношении к ним. В 1940 г. русские расстреляли 15000 польских офицеров, а еще говорят, что поляки их друзья [6, л. 70].

14 сентября 1949 г. в оперативный отдел поступило агентурное сообщение о том, что в 1-м лаготделении образовался «КДУ - клуб нерентабельных». Его члены поставили перед собой задачу не работать и вести пропаганду среди других военнопленных за сокращение и ухудшение работы, а именно: давать $14 \%$ вместо 140. Своим товарищам они заявляли: 
- В том, что мы находимся в плену, виноваты сами военнопленные, которые из месяца в месяц поднимают процент производительности и темпы работы. Русские нас используют рентабельно и оттягивают отправку на родину. Если бы мы еще в 1946-1948 гг. давали по 10-15\%, то были бы уже дома. Надо быть бесполезными и тогда быстро начнется репатриация. В числе репатриируемых военнопленных - «ОК» (ослабленная команда. $-A$. E. ), дистрофики и инвалиды, которых русские не могли использовать на работах. Остались только здоровые и специалисты. Обещание о том, что лучшие рабочие будут репатриированы, остались только обещаниями. Когда наши рабовладельцы заметят, что мы плохо работаем, то они некоторых посадят в карцер или отлупят. Если это будут делать все военнопленные, то они будут вынуждены отправить нас на родину [6, л. 129].

Принимая во внимание характер указанных взысканий, а также тот эффект, который они производят среди основной массы заключенных, лагерные чекисты вынуждены были уже в апреле 1949 г. обратиться в областное Управление МВД с просьбой разрешить им привлечение к уголовной ответственности тех военнопленных, которые «выражают враждебные и реакционные настроения против СССР и стран народной демократии». По этим же соображениям 23 ноября 1949 г. приказом МВД СССР переписка осужденных и подследственных военнопленных с родственниками была запрещена.

\section{Обеспечение фильтрации режимного контингента}

При рассмотренных выше обстоятельствах происходило выполнение лагерем его основных задач, главной из которых была фильтрация подучетного элемента и подготовка репатриации. С целью проведения соответствующих мероприятий в каждом лагерном отделении были созданы оперативные группы из расчета 1 оперативник и 1 переводчик на 75 заключенных. Для содержания военнопленных на время допросов и проведения следствия организовали специальные изолированные помещения по тюремному принципу.
Оперативно-розыскные и следственные действия в отношении подвергнутых фильтрации военнопленных ранее нами уже были детально рассмотрены [4, с. 6-16]. Наиболее характерные результаты фильтрации в режимном лагере № 108 имели место по «немецкой линии». Из 3496 немцев, содержавшихся в лагере на завершающем этапе его функционирования, арестованы и преданы суду были 899, 1960 репатриировали на родину. 27 декабря 1949 г. из режимного лагеря № 108 была отправлена последняя партия военнопленных. 5 января 1950 г. он был расформирован, а его основные отделения переданы под размещение советских заключенных [8, л. 134].

Выводы: изложенное позволяет прийти к выводу о том, что во второй половине 1940-х гг. в Советском Союзе от репатриации на родину была отведена значительная часть военнопленных вермахта, которые в силу характера своих прежних служебных обязанностей были косвенно или предположительно причастны к злодеяниям на оккупированной территории СССР. Для их содержания, оперативно-следственной разработки и трудоиспользования МВД СССР был организован ряд специализированных режимных лагерей. Сталинград и его окрестности явились одним из основных мест сосредоточения военнопленных данной категории. Их пребывание в режимных лагерях само по себе явилось одной из мер внесудебной репрессии, назначенных по решению административных органов, а для значительной части также предварительной стадией уголовного преследования, главным образом по обвинению в военных преступлениях. Следует признать, что значительная часть гитлеровских военнопленных была направлена на «особый режим» ошибочно, в том числе по политическим мотивам.

\section{ПРИМЕЧАНИЕ}

${ }^{1}$ Исследование выполнено при поддержке РГНФ (ныне РФФИ) в рамках проекта «Советские судебные процессы над военными преступниками в 1943-1991 гг.: цели, функции и эффекты избирательной медиатизации» № 16-21-08001. 


\section{ТЕОРИЯ И ПРАКТИКА ГОСУДАРСТВЕННО-ПРАВОВОГО РАЗВИТИЯ}

\section{СПИСОК ЛИТЕРАТУРЫ}

1. Архив Информационного центра (ИЦ) Главного управления внутренних дел (ГУВД) Волгоградской обл. Ф. 6. Оп. 1. Д. 262.

2. Архив ИЦ ГУВД Волгоградской обл. Ф. 6. Оп. 1. Д. 361.

3. Архив ИЦ ГУВД Волгоградской обл. Ф. 6. Оп. 1. Д. 370.

4. Епифанов, А. Е. Преследование военных преступников среди военнопленных вермахта в СССР (историко-правовой аспект) / А. Е. Епифанов // Право и практика. -2017. - № 4. - С. 6-16.

5. Российский государственный военный архив (РГВА). Ф. 1/а. Оп. 15. Д. 16.

6. РГВА. Ф. 1/а. Оп. 9. Д. 10.

7. РГВА. Ф. 47/п. Оп. 14. Д. 76.

8. РГВА. Ф. 1/е. Оп. 17. Д. 33.

\section{REFERENCES}

1. Arkhiv Informatsionnogo tsentra (ITs) Glavnogo upravleniya vnutrennikh del (GUVD) Volgogradskoy obl. [Archive of Information Centre of the Chief Directorate of Interior of the Volgograd Region], F. 6, Op. 1, D. 262.
2. Arkhiv Informatsionnogo tsentra (ITs) Glavnogo upravleniya vnutrennikh del (GUVD) Volgogradskoy obl. [Archive of Information Centre of the Chief Directorate of Interior of the Volgograd Region], F. 6, Op. 1, D. 361.

3. Arkhiv Informatsionnogo tsentra (ITs) Glavnogo upravleniya vnutrennikh del (GUVD) Volgogradskoy obl. [Archive of Information Centre of the Chief Directorate of Interior of the Volgograd Region], F. 6, Op. 1, D. 370.

4. Epifanov A.E. Presledovanie voennykh prestupnikov sredi voennoplennykh vermakhta $\mathrm{V}$ SSSR (istoriko-pravovoy aspekt) [Prosecution of War Criminals among the Prisoners of Wehrmacht in the USSR (Historical and Legal Aspect). Pravo i praktika [The Law and Practice], 2017, no. 4, pp. 6-16.

5. Rossiyskiy gosudarstvennyy voennyy arkhiv [Russian State Military Archive], F. 1/a, Op. 15, D. 16.

6. Rossiyskiy gosudarstvennyy voennyy arkhiv [Russian State Military Archive], F. 1/a, Op. 9, D. 10 .

7. Rossiyskiy gosudarstvennyy voennyy arkhiv [Russian State MilitaryArchive], F. 47/p, Op. 14, D. 76 .

8. Rossiyskiy gosudarstvennyy voennyy arkhiv [Russian State Military Archive], F. 1/e, Op. 17, D. 33.

\section{Information about the Author}

Aleksandr E. Epifanov, Doctor of Sciences (Jurisprudence), Professor, Department of Constitutional and Municipal Law, Volgograd State University, Prosp. Universitetsky, 100, 400062 Volgograd, Russian Federation, kmp@volsu.ru.

\section{Информация об авторе}

Александр Егорович Епифанов, доктор юридических наук, профессор кафедры конституционного и муниципального права, Волгоградский государственный университет, просп. Университетский, 100, 400062 г. Волгоград, Российская Федерация, kmp@volsu.ru. 